\title{
Peningkatan Kualitas Produksi dan Pemasaran Produk Bandeng Presto di UMKM Bandeng Presto "Mbak Sofi" Semarang
}

\section{Improving the Quality of Production and Marketing of Bandeng Presto Products at UMKM Bandeng Presto "Mbak Sofi" Semarang}

\author{
Fafa Nurdyansyah, M. Khoiron Ferdiansyah, Arief Rahman Affandi, Umar Hafidz \\ Asy'ari Hasbullah \\ Program Studi Teknologi Pangan Universitas PGRI Semarang, Semarang, Indonesia \\ fafanudyansyah@upgris.ac.id, ariefraffandi@,upgris.ac.id
}

Riwayat Artikel: Dikirim 24 Juli 2020; Diterima 6 November 2020; Diterbitkan 30 November 2020

\begin{abstract}
Abstrak
Bandeng merupakan salah satu komoditas perairan yang memiliki banyak potensi untuk dikembangkan, salah satunya adalah bandeng presto di Kota Semarang. UMKM Bandeng Mbak Sofi adalah salah satu UMKM yang mengolah bandeng segar menjadi bandeng presto. Namun pengolah bandeng di UMKM ini masih tergolong sederhana dan belum ada manajemen pengelolaan UMKM yang baik. Pengabdian ini bertujuan untuk membantu UMKM Bandeng Mbak Sofi dalam upaya peningkatan inovasi dan kualitas pengolahan bandeng yang diproduksi serta manajemen pengelolaannya. Permasalahan utama yang dihadapi oleh mitra yaitu umur simpan bandeng presto yang relatif singkat, terbatasnya sarana dan prasarana untuk proses pengolahan, manajemen pengelolaan UMKM, serta pemasaran. Beberapa langkah yang akan dilakukan untuk terlaksananya program ini adalah penyediaan sarana prasarana pendukung proses pengolahan, inovasi pengolahan bandeng. Selain itu untuk proses yang berkaitan dengan regulasi telah dilakukan penerbitan PIRT untuk produk bandeng presto dan produk lainnya. Kurangnya kreativitas dalam pengolahan dapat diberikan solusi dengan peningkatan inovasi produk berbahan dasar ikan bandeng. Manajemen produksi, keuangan, distribusi serta pemasaran juga akan menjadi fokus dalam program ini. Dengan terlaksananya program pengabdian ini dihasilkan kualitas bandeng presto yang lebih baik dan mampu bersaing di pasaran yang lebih luas.
\end{abstract}

Kata kunci: Bandeng, Kualitas, Pemasaran, Pengabdian, UMKM.

\begin{abstract}
Milkfish is a marine commodity that has a lot of potential to be developed, one of which is soft-boned milkfish in Semarang City. Mbak Sofi's Milkfish Micro, Small and Medium Enterprise (MSME) of "Bandeng Mbak Sofi" is one of the MSMEs that processes fresh milkefish into soft-boned milkefish. However, the milk.fish processing in the MSME is still relatively simple and there is no good management of MSME management. This service aims to belp Mbak Sofi's milkefish MSME in an effort to increase innovation and quality of the milkefish processing produced and its management. The main problems faced by the partner are the relatively short shelf life of soft-boned milkefish, limited facilities and infrastructure for processing, management of MSME management, and marketing. Some of the steps that will be taken for the implementation of this program are the provision of supporting infrastructure for the processing and the innovation of milkfish processing. In addition, for regulatory processes, PIRT has been issued for soft-boned milkfish products and other products. Lack of creativity in processing can be given a solution by increasing the innovation of milk-fish-based products. Production management, finance, distribution and marketing will also be the focus of this program. With the implementation of this service program, the quality of the soft-boned milkfish is better and is able to compete in a wider market.
\end{abstract}

Keywords: Milkfish, Quality, Marketing, Community Service, MSME

\section{PENDAHULUAN}

Kota Semarang sebagai salah satu kota penting di Provinsi Jawa Tengah memiliki ikon oleh-oleh yaitu bandeng presto yang banyak diproduksi oleh UKM yang banyak tersebar di kota tersebut. Contoh UKM yang mengolah bandeng menjadi bandeng presto yaitu UMKM Bandeng Presto Tego yang ada di Kelurahan Srondol Wetan, Kecamatan Banyumanik, Kota Semarang. 
Jumlah bandeng yang dibutuhkan per harinya untuk diolah menjadi bandeng presto yaitu sekitar $50 \mathrm{~kg}$ yang didapatkan dari pasar setempat. Jika jumlah bahan baku dari pasar kurang memadai, pemilik usaha mengambil bahan baku dari petani tambak bandeng masyarakat sekitar. Namun selama ini tidak banyak kendala berkaitan dengan penyediaan bahan mentah. Bandeng yang dipanen umumnya langsung diolah dalam bentuk segar sehingga kualitas bandeng presto yang dihasilkan dapat dipertahankan. Selama ini ketersediaan bandeng untuk produksi tidak mengalami kendala karena pemasok bahan baku selalu rutin memasok bandeng kepada UMKM. Spesifikasi bandeng yang diolah adalah bandeng yang berukuran sedang dan memiliki tingkat kesegaran yang cukup tinggi.

Bandeng presto yang dihasilkan oleh UMKM melalui proses produksi yang sederhana yaitu dengan alat presto kapasitas sedang, yang memiliki kapasitas antara 5 sampai dengan $25 \mathrm{~kg}$, serta alat pengolahan manual lain. Proses pengolahan bandeng segar menjadi bandeng presto melalui beberapa tahapan yaitu pembersihan bandeng, pemberian bumbu, pelunakan duri menggunakan alat presto, dan pengemasan. Proses produksi dilakukan di rumah dan menjadi satu dengan tempat tinggal pemilik usaha. Sistem produksi yang masih sederhana dapat dilihat dari penggunaan peralatan yang cukup sederhana serta urutan tahap pengolahan yang dilakukan secara batch. Layout pada ruang produksi belum disusun secara sistematis dan belum mengikuti alur proses produksi yang seharusnya.

Produk bandeng presto memiliki cita rasa yang gurih, dimana cita rasa tersebut berasal dari kandungan lemak yang ada pada ikan bandeng dan juga dari bumbu yang diberikan selama proses pengolahan berlangsung. Produk bandeng duri lunak memiliki ketampakan mengkilat dengan warna kekuningan yang berasal dari bumbu yang ditambahkan. Selain itu aroma yang dihasilkan adalah aroma khas bandeng tanpa ada aroma busuk yang menandakan bahwa bandeng tersebut telah mengalami kerusakan. Bandeng presto yang diproduksi di UMKM Bandeng Mbak Sofi hanya menggunakan kemasan plastik biasa, selain itu juga masih belum terdapat pengemasan sekunder berupa kardus untuk meminimalisir kerusakan. Sistem pengemasan primer menggunakan plastik PP, sedangkan pengemasan sekunder menggunakan kertas karton (dus). Setiap dus berisi 2 buah bandeng berukuran sedang. Dalam 1 hari, jumlah minimal bandeng yang diolah yaitu $20 \mathrm{~kg}$.

Untuk dapat sampai ke tangan konsumen, produk bandeng presto didistribusikan dengan kondisi pengemasan dan suhu pengangkutan yang kurang terkendali. Umumnya bandeng duri lunak tidak mampu bertahan lebih dari 2 hari jika disimpan pada suhu ruang. Penyimpanan pada suhu rendah (refrigerant maupun freezer) diperlukan untuk mempertahankan mutu bandeng duri lunak selama penyimpanan hingga sampai ke tangan konsumen. Jika ditinjau dari segi pengemasan, UMKM Bandeng Mbak Sofi belum menggunakan pengemas vakum, sehingga kualitas bandeng duri lunak selama penyimpanan kurang bisa dipertahankan. Sehingga dibutuhkan solusi untuk meningkatkan kualitas produksi bandeng presto di UMKM Mbak Sofi serta bagaimana pemasaran yang lebih baik.

\section{METODE}

Pelaksanaan kegiatan PKM ini berlangsung selama 3 bulan. Kegiatan dilaksanakan di UMKM Bandeng Mbak Sofi, Kelurahan Srondol Wetan, Kecamatan Banyumanik, Kota Semarang, Jawa Tengah yang berjarak $10 \mathrm{~km}$ dari Universitas PGRI Semarang.

Metode pelaksanaan kegiatan PKM ini melalui pemberdayaan masyarakat dan UMKM serta optimalisasi mitra dengan menawarkan solusi mengenai perijinan PIRT serta peningkatan kualitas produk bandeng presto melalui pengemasan dan pemasaran produk. 
Tahapan pelaksanaan program pengabdian kepada masyarakat tersebut adalah sebagai berikut:

\section{Sosialisasi program kegiatan PKM}

Pada tahap awal kegiatan PKM ini dilakukan survei terhadap kelayakan mitra, dimana dilakukan analisis situasi dan permasalahan yang dihadapi oleh mitra. Berdasarkan hasil survei tersebut kemudian dilakukan kegiatan sosialisasi mengenai penanganan masalah mitra. Peserta sosialisasi akan diberikan pemahaman mitra mengenai tahapan standarisasi pemilihan bahan baku dan kualitasnya. Kegiatan ini bertujuan untuk memberi pemahaman dan menumbuhkan kesadaran kepada mitra untuk mengoptimalkan serta memanfaatkan sumber daya yang ada sehingga diharapkan tujuan program PKM dapat terwujud.

\section{Pembinaan inovasi pengemasan dan manajemen pemasaran daring (online)}

Pada tahap ini tim PKM melaksanakan kegiatan berupa pelatihan dan pembinaan mengenai praktik dan teknik mengemas produk olahan bandeng dengan berbagai jenis pengemas yang sesuai serta menentukan umur simpang produk. Pendampingan pada tahap ini dimaksudkan agar mitra mampu membuat serta mengelola rintisan usaha yang dikelola secara mandiri.

Selain itu juga diberikan pelatihan mengenai sistem pemasaran produk daring, hal ini bertujuan untuk memanfaatkan internet sebagai media dan alat bantu dalam memasarkan produk hasil kegiatan dalam skala lebih luas. Pelatihan akan dilakukan sebanyak 3 kali dengan target peserta adalah mitra UMKM dan masyarakat sekitar. Dari pelatihan ini diharapkan kelompok mitra dapat mengelola serta memasarkan produk daring.

\section{Evaluasi dan pendampingan program \\ Evaluasi dan pendampingan} dilakukan pada tahap akhir kegiatan. Tujuan dari kegiatan ini yaitu untuk melakukan evaluasi terhadap program yang sudah dijalankan. Evaluasi terhadap proses juga dilakukan untuk mengontrol jalannya program, perbaikan proses akan dilakukan berdasarkan adanya kekurangan selama proses evaluasi program PKM. Kegiatan pendampingan dilaksanakan terhadap mitra dalam setiap tahap pelaksanaannya dalam menjalankan pengembangan usaha dan sistem manajemen yang lebih baik.

\section{HASIL DAN PEMBAHASAN}

Pelaksanaan program Pengabdian Kepada Masyarakat yang telah dilakukan di UMKM Bandeng Mbak Sofi, Kelurahan Srondol Wetan, Kecamatan Banyumanik Kota Semarang merupakan rangkaian kegiatan untuk peningkatan keterampilan UMKM dalam pengolahan dan perijinan produksi ikan bandeng menggunakan alat presto.

Adapun rincian kegiatan serta hasilnya antara lain:

\section{Pengurusan PIRT produk UMKM Bandeng Mbak Sofi}

Pendampingan pengurusan izin PIRT bagi UMKM mbak Sofi dimulai dengan pengambilan formulir dan pengisian berkas kelengkapan untuk pendaftaran izin PIRT. Perizinan PIRT terdaftar pada dinas kesehatan setempat dalam hal ini Dinas Kesehatan Kota Semarang. Pengisian identitas produk dilakukan oleh pemilik UMKM bandeng Mbak Sofi dengan menyertakan surat pengantar yang ditandatangani oleh Kelurahan setempat. Setelah itu tim PKM pendamping melakukan survei kelapangan tempat produksi untuk melihat secara langsung kelayakan produksi bandeng presto dan Wingko babat yang diproduksi oleh UMKM tersebut. 
Gambar 1:

Tim Mendampingi Survei Perijinan PIRT

Dinkes Kota Semarang

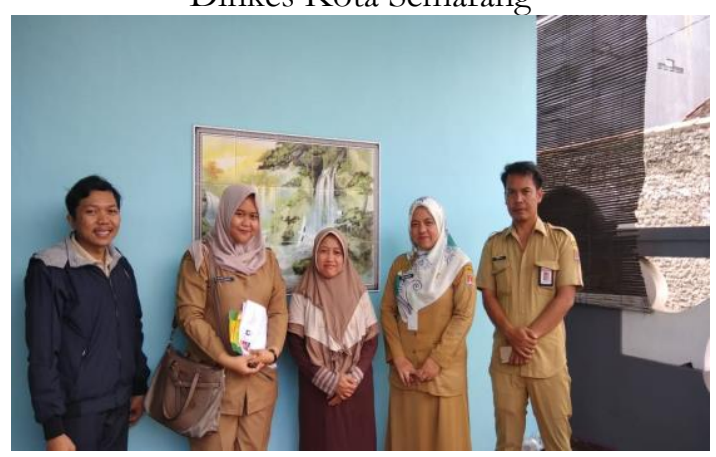

Sumber: Dokumentasi Pribadi

Langkah selanjutnya dalam pengurusan PIRT yaitu pemilik UMKM diwajibkan untuk mengikuti kegiatan penyuluhan yang diadakan oleh dinas kesehatan Kota Semarang. Materi yang diberikan berupa izin edar makanan, keamanan pangan, dan pelabelan produk pangan.

Dengan adanya penyuluhan atau sosialisasi ini dapat meningkatkan kesadaran pelaku UMKM dalam memproduksi makanan yang baik dan sesuai dengan ketentuan keamanan pangan dari pemerintah. Pemberian izin PIRT ini tidak hanya melihat kondisi yang terjadi pada UMKM.

Para pelaku usaha juga akan diberikan pelatihan dan penyuluhan tentang cara memilih bahan baku yang baik, proses produksi yang aman, bebas dari cemaran, dan proses penanganan produk akhir yang tepat. Seluruh kegiatan tersebut dapat meningkatkan manajemen para pelaku UKM untuk memberikan hasil olahan produk yang baik kepada konsumen dari segi kualitas produk maupun keamanannya.

Untuk membuktikan serta mengevaluasi cara memproduksi makanan yang baik dan benar maka tahapan selanjutnya yang harus dilalui oleh UMKM dalam pengajuan PIRT yaitu kegiatan survei yang dilakukan oleh dinas kesehatan. Kegiatan survei dilakukan setelah pemilik usaha mengikuti kegiatan penyuluhan, dengan agenda kegiatan pengecekan secara langsung kegiatan produksi bandeng presto dan wingko babat, peralatan yang digunakan, kebersihan tempat produksi, serta penyimpanan produk.

Setelah kegiatan survei dilakukan, ada beberapa temuan yang perlu diperhatikan dalam kegiatan produksi bandeng presto dan wingko babat, antara lain pada saat produksi UMKM belum menggunakan masker sehingga ke depan pelaku UMKM menggunakan masker saat memproduksi makanan sehingga dapat menghindari terjadinya kontaminasi saat produksi. Kemudian temuan yang lain yaitu untuk bagian kemasan produk.

Kemasan yang dibuat oleh pihak UMKM belum memiliki keterangan label yang sesuai dengan ketentuan dari PIRT seperti, terdapat nama produk, alamat produksi, kode produksi, masa kadaluwarsa produk, nomor PIRT, komposisi produk, dan Netto. Dengan demikian tim PKM dari Universitas PGRI melakukan pendampingan terhadap pembuatan label atau kemasan yang baik untuk UMKM Bandeng Mbak Sofi hingga sampai terbit surat perijinan PIRT.

\section{Gambar 2:}

Pendampingan PIRT UMKM Mbak Sofi

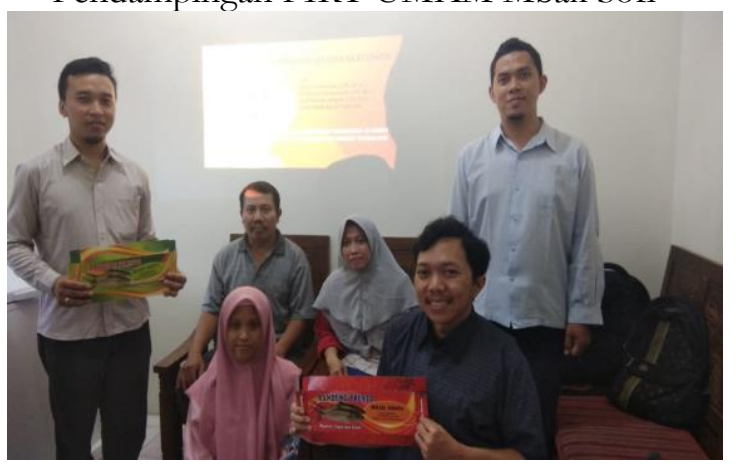


Gambar 3 :

Sertifikat PIRT UMKM Mbak Sofi

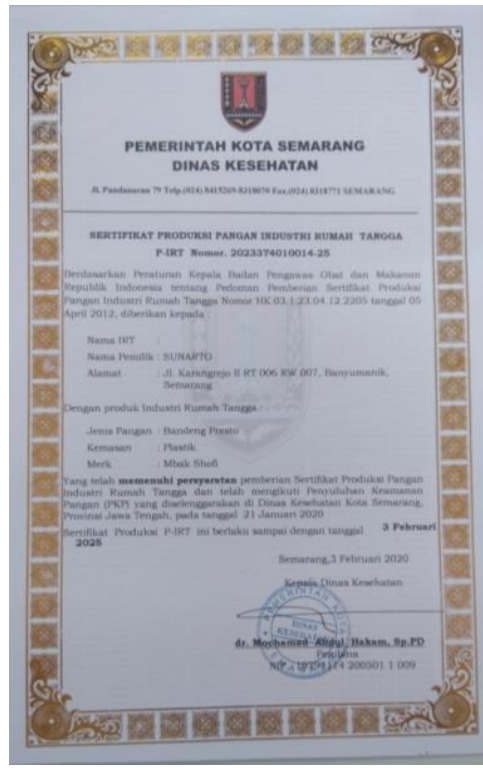

\section{Pelatihan Pengemasan Produk UMKM Bandeng Mbak Sofi}

Rangkaian kegiatan pengabdian kepada masyarakat dilanjutkan dengan pelatihan pengemasan produk dengan kemasan yang menarik, dan membuat produk menjadi tahan lama. Pemberian pelatihan pengemasan produk dan promosi penjualan produk olahan ikan bandeng ditujukan untuk memberikan wawasan serta kemampuan dalam mengemas produk menjadi menarik dan mampu bersaing dengan produk di pasaran serta untuk meningkatkan kemampuan peserta dalam menjual produknya di pasaran.

Hasil produk olahan ikan bandeng yang telah dibuat oleh UMKM Mbak Sofi awalnya hanya berupa kemasan yang dibuat sangat sederhana yaitu menggunakan daun bambu sehingga kurang menarik bagi konsumen dan memiliki umur simpan yang lebih rendah. Oleh karena itu tim PKM Universitas berupaya untuk melakukan sosialisasi serta perbaikan terhadap kemasan produk yang sudah ada sehingga mampu meningkatkan kualitas dan umur simpan produk.
Gambar 4:

Penampilan Produk sebelum dikemas

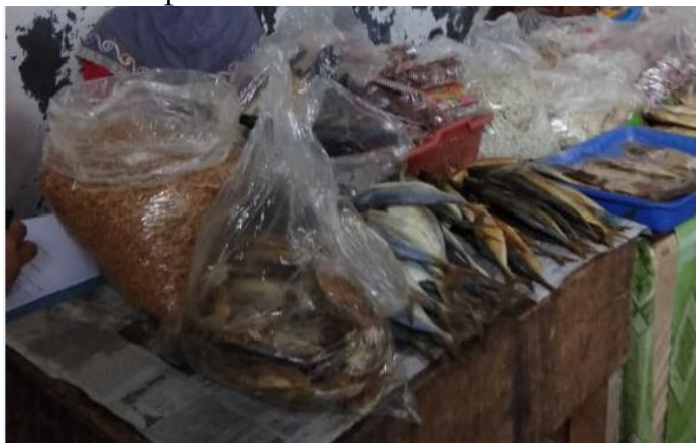

Gambar 5 :

Kemasan produk bandeng presto hasil pendampingan oleh Tim PKM Universitas

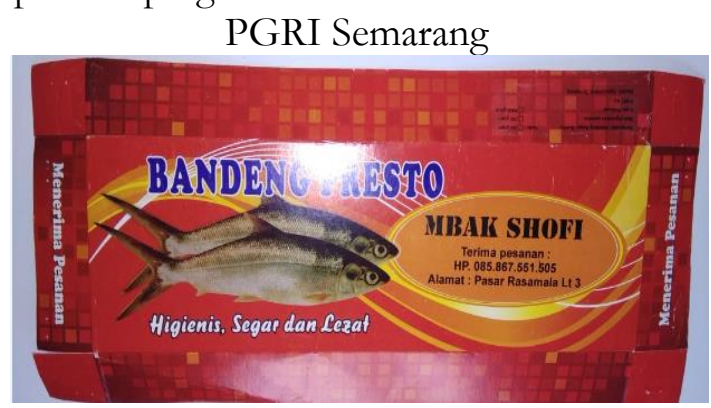

\section{Pelatihan Pemasaran Daring}

Manajemen finansial dan pemasaran daring merupakan salah satu faktor yang penting dalam membuka usaha, hal inilah yang menjadi dasar pelatihan manajemen finansial dan pemasaran daring. Berkembangnya teknologi menjadi dasar bahwa penggunaan sistem daring sangat membantu dalam proses wirausaha mandiri. Tim Pengabdian Universitas PGRI Semarang memberikan pelatihan kepada warga masyarakat terutama ibu-ibu dalam manajemen pengelolaan keuangan serta bagaimana pemasaran produk yang telah dibuat dengan menggunakan sarana daring. Pemanfaatan media sosial untuk pemasaran daring dapat digunakan untuk peluang mencari konsumen atau pelanggan dengan cara yang efektif dan efisien untuk saat ini karena dengan kemudahan akses dan kemudahan penggunaan membuat setiap orang selalu menggunakan media sosial. 
Gambar 6 :

Pelatihan Manajemen dan pemasaran daring bagi mitra pengabdian

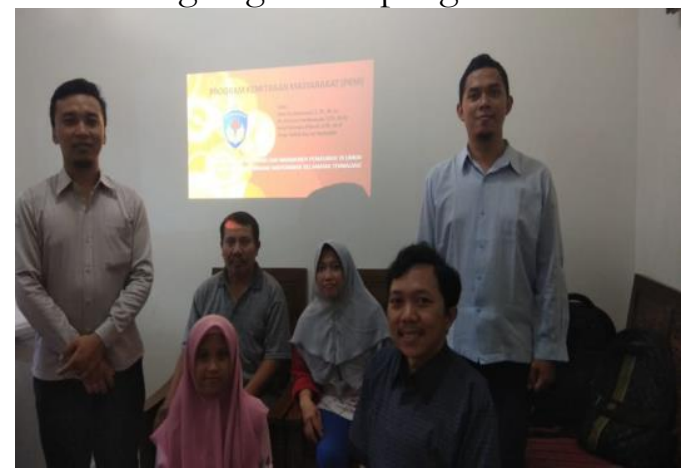

\section{KESIMPULAN}

Berdasarkan hasil kegiatan pelaksanaan Pengabdian kepada masyarakat didapatkan kesimpulan yaitu pelaksanaan kegiatan pengabdian kepada masyarakat berlangsung dengan baik dan mitra sangat antusias dengan kegiatan PKM. Pada pelaksanaan PKM ini telah dihasilkan produk berupa keluarnya ijin produk UMKM Mbak Sofi dari dinas Kesehatan Kota Semarang yaitu PIRT dengan nomor 2063374020014-25.

Selain itu Tim PKM juga memberikan penyuluhan tentang kemasan produk yang inovatif dan menarik bagi konsumen. Tim PKM juga memfasilitasi pelatihan penjualan atau pemasaran secara daring sehingga dapat meningkatkan promosi penjualan produk yang lebih luas dan mampu bersaing dengan produk lain. Dengan berakhirnya kegiatan ini maka mitra sangat terbantu dalam pengembangan produk UMKM yang dikelola dan dapat meningkatkan nilai jual yang lebih baik lagi.

\section{DAFTAR PUSTAKA}

Adawyah, R. (2008). Pengolahan dan Pengawetan Ikan. ed. 1, cet. 3. Bumi Aksara: Jakarta.

Afrianto, I. E., \& Liviawaty, I. E. (1989). Pengawetan dan pengolahan ikan. Kanisius.

Girard, J. P. (1992). Technology of meat and meat products. New York. Ellis Horwood.
Himawati, E. (2010). Pengaruh penambahan asap cair tempurung kelapa destilasi dan redestilasi terhadap sifat kimia, mikrobiologi, dan sensoris ikan pindang Layang (Decapterus spp) selama penyimpanan.

Mulyati, D. S., \& Bachtiar, I. (2014). IbM Kelompok Kegiatan di Komplek Budi Indah Kelurahan Pasirkaliki Kecamatan Cimahi Utara Kota Cimahi. Prosiding SNaPP: Sains, Teknologi, 4(1), 341-348.

Rasydta, H. P. (2013). Penggunaan asap cair tempurung kelapa dalam pengawetan ikan Bandeng (Doctoral dissertation, Universitas Negeri Semarang).

Robert L. Mott. (2009). Elemen- Elemen Alat Dalam Perancangan Mekanis Buku 1.Yogyakarta: Andi

Rohmansyah, N. A., Nurdyansyah, F., \& Prastiwi, B. K. (2017). Pemberdayaan Masyarakat Melalui IbM Pelatihan Olahan Limbah Tahu Di Desa Drono Ngawen Klaten. Jurnal Kewirausahaan dan Bisnis, 21(11).

Saparinto, C. (2007). Membuat aneka olahan bandeng. Penebar Swadaya. Jakarta.

Umar, H. (2003). Studi Kelayakan Bisnis: Teknik Menganalisis Kelayakan Rencana Bisnis Secara Komprehensif. Jakarta: PT. Gramedia Pustaka Utama.

Widyastuti, D. A., \& Nurdyansyah, F. (2019). Pemberdayaan Wanita Tani Kabupaten Kudus dalam Pembuatan Saus Cabai (Capsicum anuum). Jurnal Surya Masyarakat, 1(2), 81-85.

Yahono, S. B. (2004). Kajian Beberapa Aspek Pengolahan Ikan Secara Tradisional dalam Upaya Peningkatan Mutu Produk Perikanan di Kabupaten Jepara (Doctoral dissertation, program Pascasarjana Universitas Diponegoro). 